\title{
NUMERICAL EVALUATION OF A NEW STRATEGY OF EMISSIONS REDUCTION BY UREA DIRECT INJECTION FOR HEAVY DUTY DIESEL ENGINES
}

\author{
Valeri I. Golovitchev**, Luca Montorsi** and Ingemar Denbratt* \\ * Department of Applied Mechanics, Chalmers University of Technology, S-41296 Gothenburg, Sweden \\ ${ }^{+}$E-Mail: valeri@chalmers.se (Corresponding Author) \\ **DISMI - University of Modena and Reggio Emilia, Via Amendola, 2 - Padiglione Morselli, \\ 42100 Reggio Emilia, Italy
}

\begin{abstract}
The effect of ammoniac deoxidizing agent (Urea) on the reduction of NOx produced in the Diesel engine was investigated numerically. Urea dissolved in water was directly injected into the engine cylinder during the expansion stroke. The NOx deoxidizing process was described using a simplified chemical kinetic model coupled with the comprehensive kinetics of Diesel oil surrogate combustion. If the technology of DWI (Direct Water Injection) with the later injection timing was used, the deoxidizing reactants could be delivered in a controlled amount directly into the flame plume zones, where NOx formed. Numerical simulations for the Isotta Fraschini DI Diesel engine were carried out using the KIVA-3V code, modified to account for the "co-fuel" injection and reaction with combustion products. The results showed that the amount of NOx could be substantially reduced up to $80 \%$ with the injection timing and the fraction of Urea in the solution optimized.
\end{abstract}

Keywords: diesel spray-combustion simulation, emission reduction, in-cylinder water and Urea injection

\section{INTRODUCTION}

To reduce the NOx level by up to $90 \%$, the SCR (Selective Catalytic Reduction) technique has been proposed and realized (Rota et al., 2002). With this method, the exhaust gas is mixed with ammonia $\mathrm{NH}_{3}$ or Urea $\left(\mathrm{NH}_{2}\right) 2 \mathrm{CO}$ (as $\mathrm{NH}_{3}$ source) before passing through a special catalyst at a temperature between $300{ }^{\circ} \mathrm{C}$ and $400{ }^{\circ} \mathrm{C}$, whereby $\mathrm{NOx}$ is converted into $\mathrm{N}_{2}$ and $\mathrm{H}_{2} \mathrm{O}$. The method is used currently in stationary power-plants, and successful applications to motor vehicles have been published in the work of Lepperhof, Huthwohl and Pischinger (1992). Reducing NOx by means of Urea SCR can only take place in the narrow temperature window, because if the temperature is too high, $\mathrm{NH}_{3}$ will burn rather than react forming $\mathrm{NO} / \mathrm{NO}_{2}$. At low temperatures and loads, the conversion rate becomes too low as illustrated in Fig. 1 by predictions made by Dr. Kusaka (2006). The amount of Urea injected into the exhaust gas is controlled by the process in proportion to the volume of NOx produced by combustion depending on the engine load.

Another possible technique that can be referenced is the so-called HAM (Humid Air Motors), where
NOx reduction is achieved by reducing the maximum combustion temperature and oxygen content by adding in the intake air inert media with high specific heat capacity: exhaust gas or steam. In the case of steam, only particulate emission can be reduced, but not NOx as illustrated by the $\phi$-T parametric emission maps in Fig. 2. The maps are constructed in a way similar to those documented by Akihama et al. (2001). By using the aqueous Urea, both soot and NOx reduction could be expected. In this way, there is no necessity for the catalytic block, and water quality in aqueous Urea can be diminished. However, the NOx conversion process is difficult to optimize since $\mathrm{NH}_{3}$ will be homogeneously distributed within the cylinder to the low and high temperature zones. This can destroy completely the effect of NOx reduction.

There is another option based on the DWI (Direct Water Injection) concept, employing a direct postinjection of the aqueous Urea as a "co-fuel" into the cylinder during the expansion stroke at the moment when pressure and temperature will reach the levels optimal for NOx conversion (Miyamoto et al., 1993). In this work, separate injectors were used to inject fuel and deoxidizing agents into the combustion region. The experimental results for 
both water and aqueous Urea are presented in Fig. 3. If the injection timing and the amount of Urea injected are properly selected, the substantial reduction of NOx can be achieved. Since the injection timing range is narrow, the selection of its optimal value requires an accurate evaluation. If the same injector is used, the reactants will be delivered in a controlled amount directly into flame zones, where NOx forms.

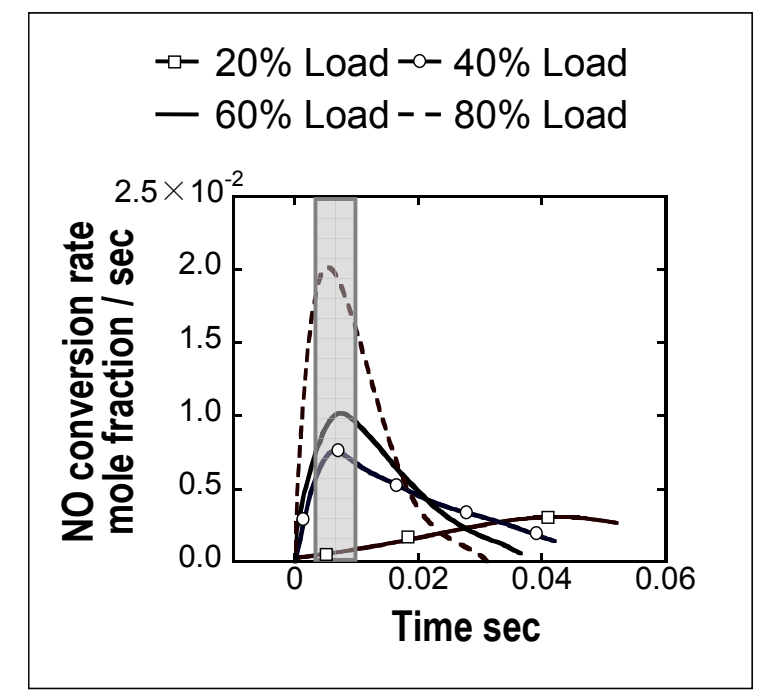

Fig. 1 The NO conversion rate in the catalytic converter as a function of the engine load (courtesy of Dr. Kusaka).

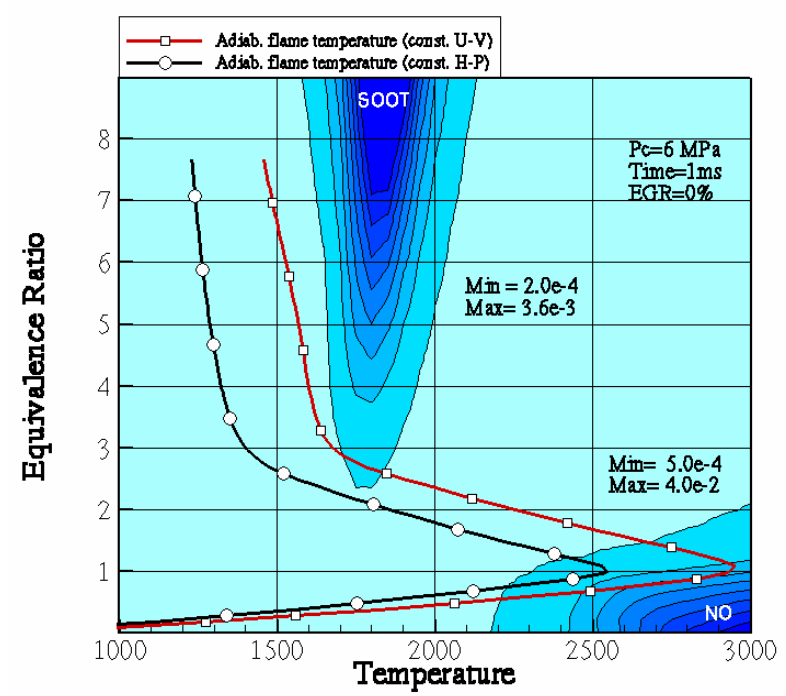

(a)

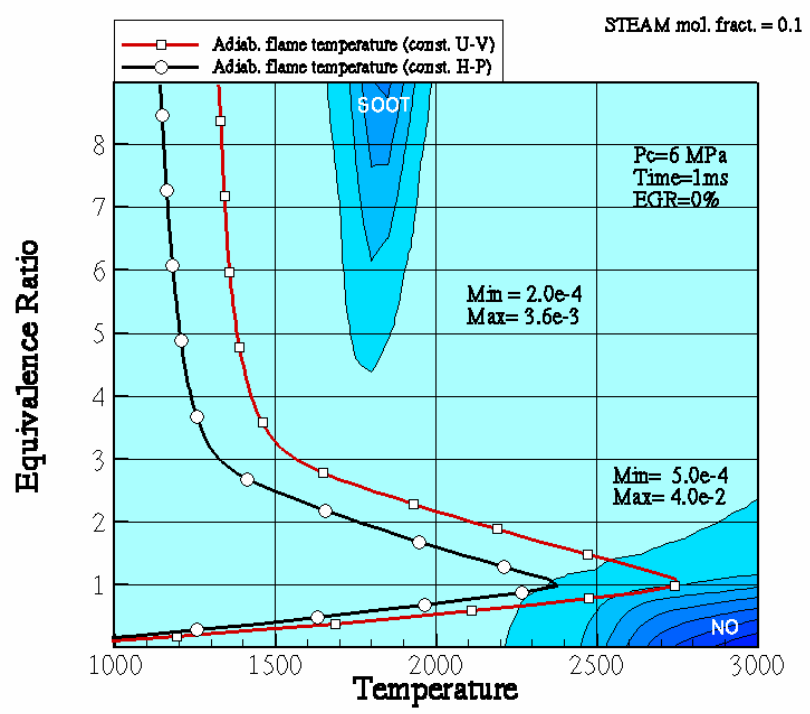

(b)

Fig. 2 Emissions Soot-NO parametric map for (a) pure air oxidizing atmosphere in the cylinder, (b) oxidizing atmosphere containing $10 \%$ (volumetric) steam. 


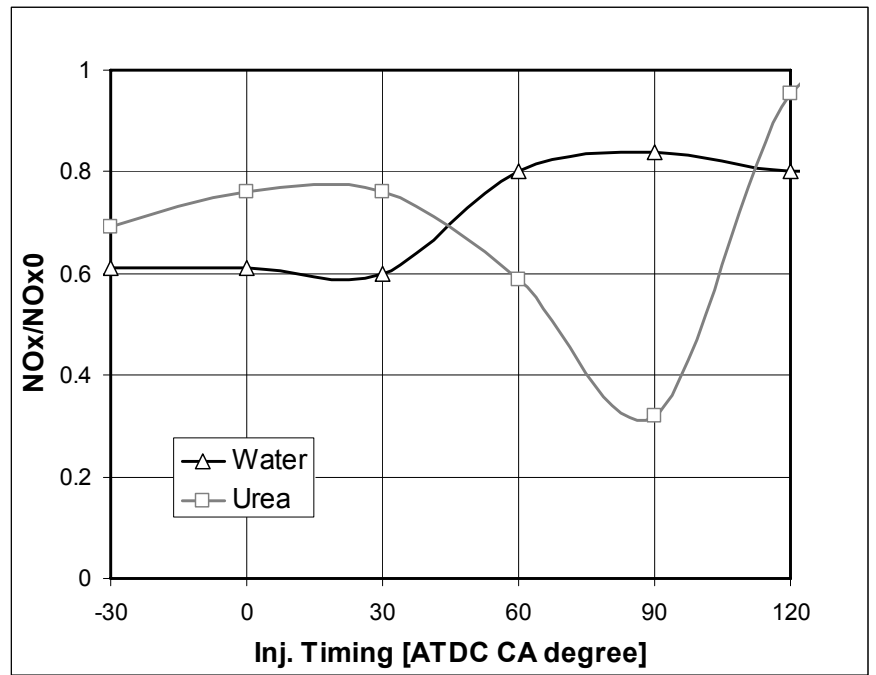

Fig. 3 Normalized (by NOx produced without Urea or water injection) NOx concentration in the cylinder as a function of injection timing.

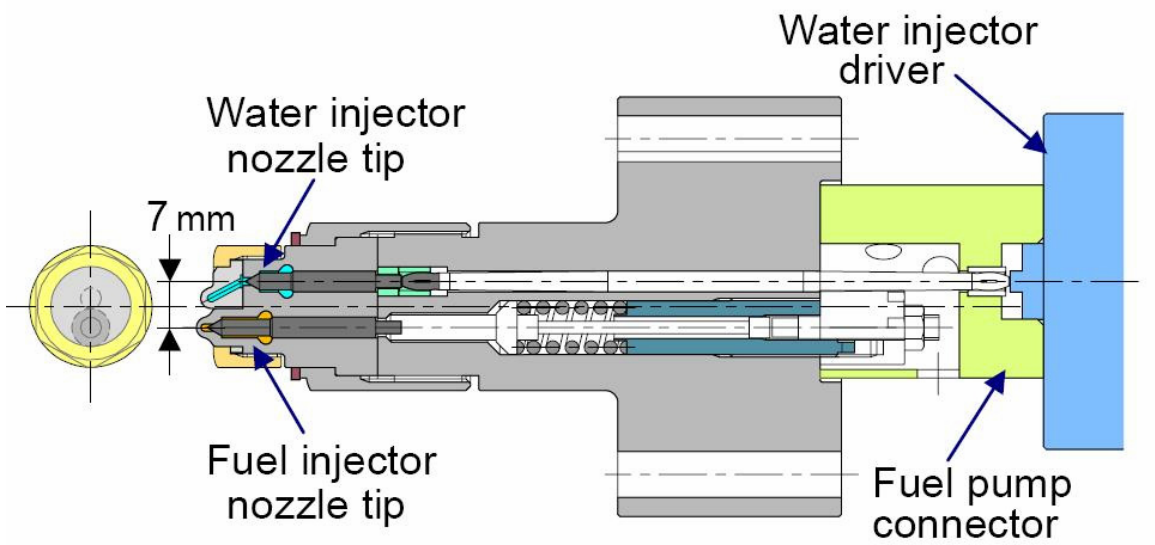

Fig. 4 Double fuel injector for the LDWI (Later Direct Water Injection) test.

Conversion of NOx by gaseous ammoniac deoxidizing agents was observed at the temperatures below $1200 \mathrm{~K}$, and NOx were found increased for higher temperatures (Canton and Siebers, 1988). The injection of the aqueous Urea and the associated water evaporation thermal effect can widen the temperature range of applicability of this NOx reduction mechanism. In this way, the earlier Urea injection can be realized giving a longer residence time for the NOx reduction process. In the study of Tajima et al. (2006), a high pressure water injection system and a special fuel and water injection nozzle were designed and manufactured for the LDWI test.

Fig. 4 represents a cross-sectional view of the special two-needle type water injector. The availability of such a device substantiates the suggestion made in this work-direct injection of NO deoxidizing agents through the same nozzle. To evaluate this option of NOx reduction, numerical simulations for the Isotta Fraschini DI Diesel engine were carried out using the KIVA-3V code (Amsden, 1997), coupled with the detailed chemistry approach for both diesel surrogate and Urea components. Since the original KIVA-3V 
code allows the injection of only one fuel strictly occupying the first position in the species list, the code was modified in order to consider different fuels independently from their position in the species list. The process of NOx reduction is illustrated also by using time transient parametric $\phi$-T maps. At first, the computational models used in the simulations will be briefly described.

\section{MODELS FOR DIESEL SPRAY COMBUSTION}

\subsection{Diesel fuel surrogate model}

Practical diesel fuels are liquid substances consisting of a great number of aliphatic, cyclic and aromatic compounds, and their combustion chemistry is too complex to be modeled using detailed chemical mechanisms for all fuel components. Instead, the models for surrogate Diesel oil are used in numerical simulations. In this paper, fuel aliphatic components are represented by n-heptane owing to its cetane number of approximately $\sim 56$, which is similar to the cetane number of conventional Diesel oil. Aromatic components significantly contribute to soot formation. The Diesel oil surrogate, which can accurately represent the auto-ignition as well as the other properties of a real fuel, is assumed to be a blend of approximately $70 \%$ of n-heptane, $\mathrm{C}_{7} \mathrm{H}_{16}$ and $30 \%$ of toluene, $\mathrm{C}_{7} \mathrm{H}_{8}$ (Gustavsson and Golovitchev, 2003).

This proportion is sustained by a formula of the global pyrolysis reaction:

$$
1.5 \mathrm{C}_{14} \mathrm{H}_{28}+0.5 \mathrm{O}_{2}=>2 \mathrm{C}_{7} \mathrm{H}_{16}+\mathrm{C}_{7} \mathrm{H}_{8}+\mathrm{H}_{2} \mathrm{O}
$$

Diesel oil surrogate model consists of two parts: the thermal / transport properties of the liquid fuel and fuel vapor and its chemical constituents. Diesel oil, as it is used in the KIVA-3V code, is a compilation of real Diesel oil properties with a proposed chemical formula $\mathrm{C}_{13} \mathrm{H}_{23}$. Since in the surrogate model, the constituent components were selected as n-heptane and toluene, and fuel decomposition is realized in the global stage (1), the fuel chemical formula has to be replaced by $\mathrm{C}_{14} \mathrm{H}_{28}$ to meet the specified proportion between the components. Then, the detailed reaction mechanisms for n-heptane and toluene oxidation have been compiled and validated using shock-tube autoignition experimental data. The complete mechanism integrating the $\mathrm{n}$-heptane and toluene oxidation chemistry coupled with the kinetics of aromatics (up to three aromatic rings) formation for rich acetylene flames was reduced on the bases of the sensitivity analysis (using the software of the Chemkin-2 package (Lutz, Kee and Miller, 1994)) to the mechanism consisting of 70 species participating in 306 reactions which is implemented into the KIVA-3V code to simulate diesel spray combustion. The mechanism includes both high and low temperature oxidation paths for aliphatic hydrocarbons and a high temperature oxidation submechanism for toluene and was proved to predict the real Diesel oil auto-ignition, combustion development and formation of polycyclic aromatic hydrocarbons (PAHs) as the gaseous soot precursors represented by acenaphthylene species, A2R5, which are non-planar aromatic rings. Soot formation mechanism consists of a series of elementary reaction steps leading from acetylene to the first aromatic ring, A1. These reaction steps are followed by the successive stages of $\mathrm{H}$-abstraction, $\mathrm{C}_{2} \mathrm{H}_{2}$-addition (HACA-mechanism), thus, yielding a chain of aromatic rings as shown in Fig. 5. Toluene can form A1 rings independently of the acetylene path mentioned.

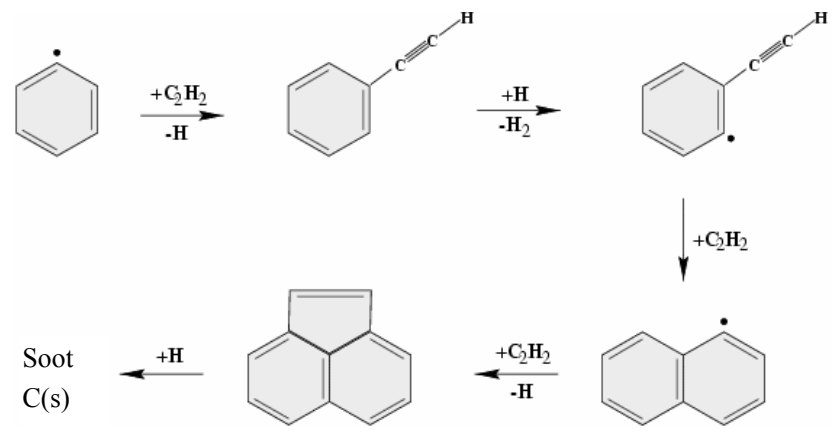

Fig. 5 Schematic of the soot formation from the gaseous precursors.

The integrated model predicts properly shock-tube auto-ignition experiments for both n-heptane and toluene, time evolutions of fuel surrogate and its constituents, and soot formation/oxidation in the course of combustion in a reasonable agreement with measurements. The electronic version of the mechanism can be found on the web site (Golovitchev, 2007).

\subsection{Nitric oxide interaction with combustion chemistry}

If there is a large amount of NOx in the mixture composition, which can be the case when using 
external or internal EGR in the conventional Diesel combustion mode, reactions for the combustion chemistry interaction with NOx species must be added:

$\mathrm{NO}+\mathrm{HO}_{2}=\mathrm{NO}_{2}+\mathrm{OH}$

$\mathrm{NO}_{2}+\mathrm{H}=\mathrm{NO}+\mathrm{OH}$

$\mathrm{NO}_{2}+\mathrm{O}=\mathrm{NO}+\mathrm{O}_{2}$

In this catalytic cycle, $\mathrm{NO}$ and $\mathrm{NO}_{2}$ species circulate interacting with the less reactive radical $\mathrm{HO}_{2}$ forming the highly reactive $\mathrm{OH}$ radical which will speed up the combustion. It is already well known that NO in the recirculated exhaust gases acts like a combustion promotor, but what is not discussed frequently is that it can also act in the opposite way, which happens if a large NO amount is present consuming $\mathrm{H}$ and $\mathrm{O}$ radicals needed for the main fuel oxidation. The Zel'dovich mechanism, supplemented by a low temperature nitrogen oxidation path via $\mathrm{N}_{2} \mathrm{O}$, has been added to supplement the NOx formation mechanism. It is instructive to note that the sub-mechanisms for soot oxidation and NOx formation are coupled with the common radical pool and the accurate prediction of both emissions is dependent on the proper balance between their oxidation rates.

\subsection{Nitric oxide interaction with Urea}

The mechanism of NO reduction by Urea includes four species participating in 17 reactions as listed in Table 1, together with the sub-mechanisms of NOx and soot oxidation. In this study, only the high temperature sub-mechanism is accounted for. The process begins with Urea decomposition. In the presence of water vapor, Urea decomposes through the following path:

Table 1 Urea/NO interaction sub-mechanism

\begin{tabular}{|c|c|c|c|c|c|c|c|c|c|}
\hline & & & & & & & A & $\mathrm{n}$ & $\mathrm{E}_{\mathrm{a}}$ \\
\hline 1 & $\mathrm{C}(\mathrm{S})$ & $+\mathrm{O}_{2}$ & & $=\mathrm{O}$ & $+\mathrm{CO}$ & & $3.00 \mathrm{E}+11$ & 0 & 12800 \\
\hline 2 & $\mathrm{C}(\mathrm{S})$ & $+\mathrm{H}_{2} \mathrm{O}$ & & $=\mathrm{CO}$ & $+\mathrm{H}_{2}$ & & $3.00 \mathrm{E}+11$ & 0 & 42800 \\
\hline 3 & $\mathrm{C}(\mathrm{S})$ & $+\mathrm{OH}$ & & $=\mathrm{CO}$ & $+\mathrm{H}^{2}$ & & $1.00 \mathrm{E}+12$ & 0 & 36800 \\
\hline 4 & $\mathrm{C}(\mathrm{S})$ & $+\mathrm{N}_{2} \mathrm{O}$ & & $=\mathrm{CO}$ & $+\mathrm{N}_{2}$ & & $3.00 \mathrm{E}+11$ & 0 & 16800 \\
\hline 5 & $\mathrm{~N}$ & $+\mathrm{NO}$ & & $=\mathrm{N}_{2}$ & $+\mathrm{O}$ & & $3.50 \mathrm{E}+13$ & 0 & 330 \\
\hline 6 & $\mathrm{~N}$ & $+\mathrm{O}_{2}$ & & $=\mathrm{NO}$ & $+\mathrm{O}$ & & $2.65 \mathrm{E}+12$ & 0 & 6400 \\
\hline 7 & $\mathrm{~N}$ & $+\mathrm{OH}$ & & $=\mathrm{NO}$ & $+\mathrm{H}$ & & $7.33 E+13$ & 0 & 1120 \\
\hline 8 & $\mathrm{~N}$ & $+\mathrm{CO}_{2}$ & & $=\mathrm{NO}$ & $+\mathrm{CO}$ & & $1.90 \mathrm{E}+11$ & 0 & 3400 \\
\hline 9 & $\mathrm{~N}_{2} \mathrm{O}$ & $+\mathrm{O}$ & & $=\mathrm{N}_{2}$ & $+\mathrm{O}_{2}$ & & $1.40 \mathrm{E}+12$ & 0 & 10810 \\
\hline 10 & $\mathrm{~N}_{2} \mathrm{O}$ & $+\mathrm{O}$ & & $=\mathrm{NO}$ & $+\mathrm{NO}$ & & $2.90 \mathrm{E}+13$ & 0 & 23150 \\
\hline 11 & $\mathrm{~N}_{2} \mathrm{O}$ & $+\mathrm{H}$ & & $=\mathrm{N}_{2}$ & $+\mathrm{OH}$ & & $4.40 \mathrm{E}+14$ & 0 & 18880 \\
\hline 12 & $\mathrm{~N}_{2} \mathrm{O}$ & $+\mathrm{OH}$ & & $=\mathrm{N}_{2}$ & $+\mathrm{HO}_{2}$ & & $2.00 \mathrm{E}+12$ & 0 & 21060 \\
\hline 13 & NO & $+\mathrm{HO}_{2}$ & & $=\mathrm{NO}_{2}$ & $+\mathrm{OH}$ & & $2.11 \mathrm{E}+12$ & 0 & -480 \\
\hline 14 & NO & $+\mathrm{O}$ & $+\mathrm{M}$ & $=\mathrm{NO}_{2}$ & $+\mathrm{M}$ & & $1.06 \mathrm{E}+20$ & -1.41 & 0 \\
\hline 15 & $\mathrm{NO}_{2}$ & $+\mathrm{O}$ & & $=\mathrm{NO}$ & $+\mathrm{O}_{2}$ & & $3.90 \mathrm{E}+12$ & 0 & -240 \\
\hline 16 & $\mathrm{NO}_{2}$ & $+\mathrm{H}$ & & $=\mathrm{NO}$ & $+\mathrm{OH}$ & & $1.32 \mathrm{E}+14$ & 0 & 360 \\
\hline 17 & $\mathrm{NO}_{2}$ & $+\mathrm{CO}$ & & $=\mathrm{CO}_{2}$ & $+\mathrm{NO}$ & & $9.00 \mathrm{E}+13$ & 0 & 33800 \\
\hline 18 & $\mathrm{NO}_{2}$ & $+\mathrm{HCO}$ & & $=\mathrm{H}$ & $+\mathrm{CO}_{2}$ & $+\mathrm{NO}$ & $8.40 \mathrm{E}+15$ & -0.75 & 1930 \\
\hline 19 & $\left(\mathrm{NH}_{2}\right)_{2 \mathrm{CO}}$ & $+\mathrm{H}_{2} \mathrm{O}$ & & $=\mathrm{NH}_{3}$ & $+\mathrm{NH}_{3}$ & $+\mathrm{CO}_{2}$ & $6.13 E+10$ & 0 & 20980 \\
\hline 20 & $\mathrm{NH}_{3}$ & $+\mathrm{M}$ & & $=\mathrm{NH}_{2}$ & $+\mathrm{H}$ & $+\mathrm{M}$ & $2.20 \mathrm{E}+16$ & 0 & 93470 \\
\hline 21 & $\mathrm{NH}_{3}$ & $+\mathrm{H}$ & & $=\mathrm{NH}_{2}$ & $+\mathrm{H}_{2}$ & & $6.36 \mathrm{E}+05$ & 2.39 & 10171 \\
\hline 22 & $\mathrm{NH}_{3}$ & $+\mathrm{O}$ & & $=\mathrm{NH}_{2}$ & $+\mathrm{OH}$ & & $9.40 \mathrm{E}+06$ & 1.94 & 6460 \\
\hline 23 & $\mathrm{NH}_{3}$ & $+\mathrm{OH}$ & & $=\mathrm{NH}_{2}$ & $+\mathrm{H}_{2} \mathrm{O}$ & & $2.00 \mathrm{E}+06$ & 2.04 & 566 \\
\hline 24 & $\mathrm{NH}_{2}$ & $+\mathrm{N}$ & & $=\mathrm{N}_{2}$ & $+\mathrm{H}$ & $+\mathrm{H}$ & $7.20 \mathrm{E}+13$ & 0 & 0 \\
\hline 25 & $\mathrm{NH}_{2}$ & $+\mathrm{NO}$ & & $=\mathrm{N}_{2}$ & $+\mathrm{H}_{2} \mathrm{O}$ & & $1.26 \mathrm{E}+16$ & -1.25 & 0 \\
\hline 26 & $\mathrm{NH}_{2}$ & $+\mathrm{H}$ & & $=\mathrm{NH}$ & $+\mathrm{H}_{2}$ & & $4.00 \mathrm{E}+13$ & 0 & 3650 \\
\hline 27 & $\mathrm{NH}_{2}$ & $+\mathrm{O}$ & & $=\mathrm{NH}$ & $+\mathrm{OH}$ & & $6.80 \mathrm{E}+12$ & 0 & 0 \\
\hline 28 & $\mathrm{NH}_{2}$ & $+\mathrm{OH}$ & & $=\mathrm{NH}$ & $+\mathrm{H}_{2} \mathrm{O}$ & & $4.00 \mathrm{E}+06$ & 2 & 1000 \\
\hline 29 & $\mathrm{NH}_{2}$ & $+\mathrm{HO}_{2}$ & & $=\mathrm{NH}_{3}$ & $+\mathrm{O}_{2}$ & & $1.00 \mathrm{E}+13$ & 0 & 0 \\
\hline 30 & $\mathrm{NH}$ & $+\mathrm{O}_{2}$ & & $=\mathrm{NO}$ & $+\mathrm{OH}$ & & $1.30 \mathrm{E}+06$ & 1.5 & 100 \\
\hline 31 & NH & $+\mathrm{NH}$ & & $=\mathrm{N}_{2}$ & $+\mathrm{H}$ & $+\mathrm{H}$ & $2.50 \mathrm{E}+13$ & 0 & 0 \\
\hline 32 & $\mathrm{NH}$ & $+\mathrm{N}$ & & $=\mathrm{N}_{2}$ & $+\mathrm{H}$ & & $3.00 \mathrm{E}+13$ & 0 & 0 \\
\hline 33 & NH & $+\mathrm{NO}$ & & $=\mathrm{N}_{2}$ & $+\mathrm{OH}$ & & $2.16 \mathrm{E}+13$ & -0.23 & 0 \\
\hline 34 & $\mathrm{NH}$ & $+\mathrm{NO}$ & & $=\mathrm{N}_{2} \mathrm{O}$ & $+\mathrm{H}$ & & $2.90 \mathrm{E}+14$ & -0.4 & 0 \\
\hline 35 & $\mathrm{~N}_{2} \mathrm{O}$ & $+\mathrm{M}$ & & $=\mathrm{N}_{2}$ & $+\mathrm{O}$ & $+\mathrm{M}$ & $1.30 \mathrm{E}+11$ & 0 & 59620 \\
\hline
\end{tabular}

Notes: Reaction rates are in $\mathrm{cm}^{3}$, mole, sec; activation energies, $\mathrm{E}_{\mathrm{a}}$, are in cal units. 


$$
\left(\mathrm{NH}_{2}\right)_{2} \mathrm{CO}+\mathrm{H}_{2} \mathrm{O}=2 \mathrm{NH}_{3}+\mathrm{CO}_{2}
$$

Due to the formation of $\mathrm{NH}_{3}$, the kinetic modeling of the system Urea/NO couples the Urea decomposition and the kinetic of the $\mathrm{NH}_{3} / \mathrm{NO}$ system (that involves the $\mathrm{NH}_{2} / \mathrm{NO}$ subsystem). Following well established sub-mechanisms, the key species for $\mathrm{NO}$ reduction is the radical $\mathrm{NH}_{2}$ formed from $\mathrm{NH}_{3}$ by hydrogen abstraction:

$\mathrm{NH}_{3}+\mathrm{OH}=\mathrm{NH}_{2}+\mathrm{H}_{2} \mathrm{O}$

The major reaction channels of NO conversion are selected as:

$\mathrm{NH}_{2}+\mathrm{NO}=\mathrm{N}_{2}+\mathrm{H}_{2} \mathrm{O}$

$\mathrm{NH}+\mathrm{NO}=\mathrm{N}_{2}+\mathrm{OH}$

Other details of the mechanisms can be found in the work of Rota et al. (2002).

\subsection{Dynamic $\varphi$-t parametric maps analysis}

Recently, in study of Akihama et al. (2001), the low emission diesel combustion regime in the presence of high EGR loads was analyzed using parametric $\phi$-T, equivalence ratio - Temperature, static maps for one component fuel coupled with a simplified 3D engine simulation. The usage of simplified combustion model in 3D simulations and static maps makes the results of such an analysis predominately qualitative.

This paper presents results of the extended analysis of such a type based on the detailed chemical model of the Diesel oil surrogate combustion. The submechanisms for the constituent components were compiled, validated using recent shock-tube autoignition data integrated together with NOx formation, PAH growth (till third aromatic ring, acenaphthylene) models, and the semi-empirical model for incipient soot formation/oxidation and used to construct the dynamic parametric $\phi$-T maps with the help of the SENKIN code (Lutz, Kee and Miller, 1994).

The maps are dynamic in the sense that when they are constructed, the map parameters, such as pressures and elapsed times, were taken in compliance with those calculated in the compression/expansion strokes of 3D engine simulations as in Fig. 6. In-cylinder conditions represented by computational cells with known $\phi$ and $\mathrm{T}$ predicted using the KIVA-3V code were then plotted on the maps, identifying combustion trajectories helping to navigate between the regions of emissions formation by varying any hardware and injection parameters.

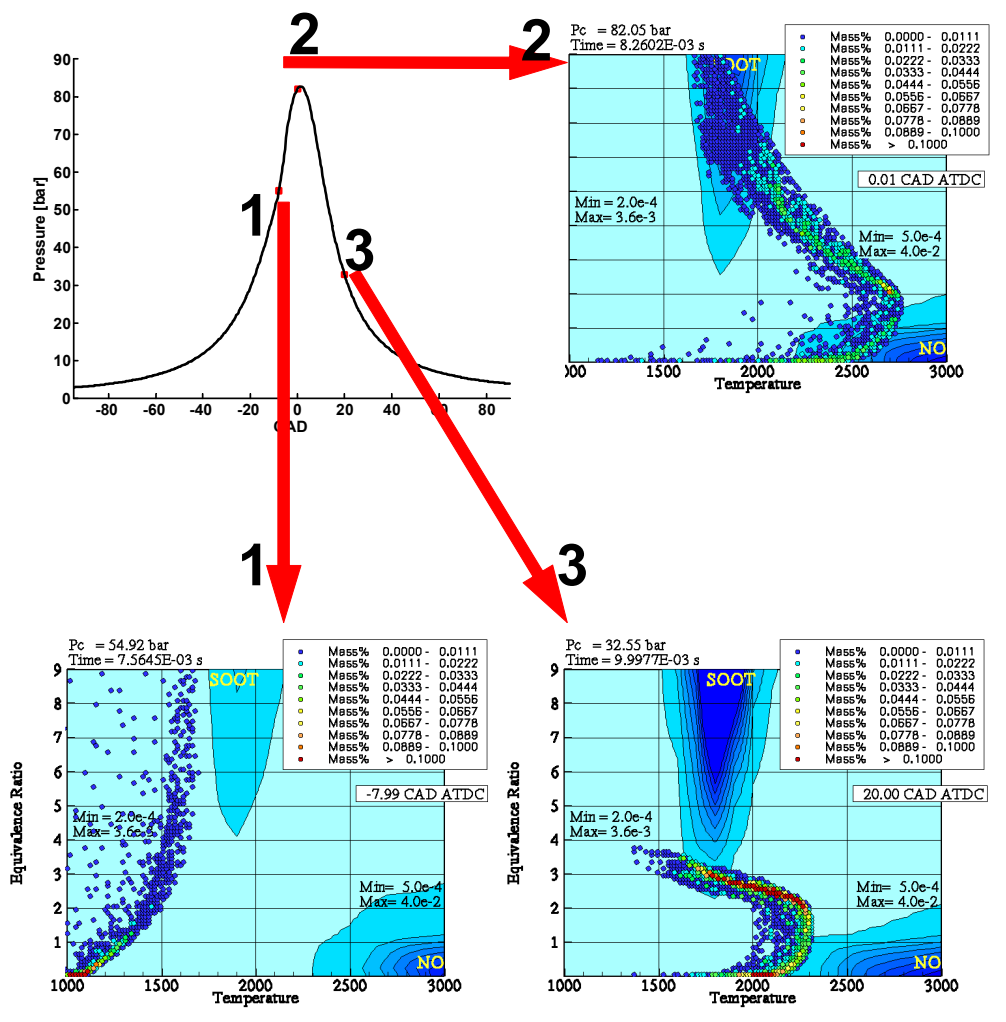

Fig. 6 The schematic of the dynamic parametric map construction; maps 1-3 correspond to different CADs. 


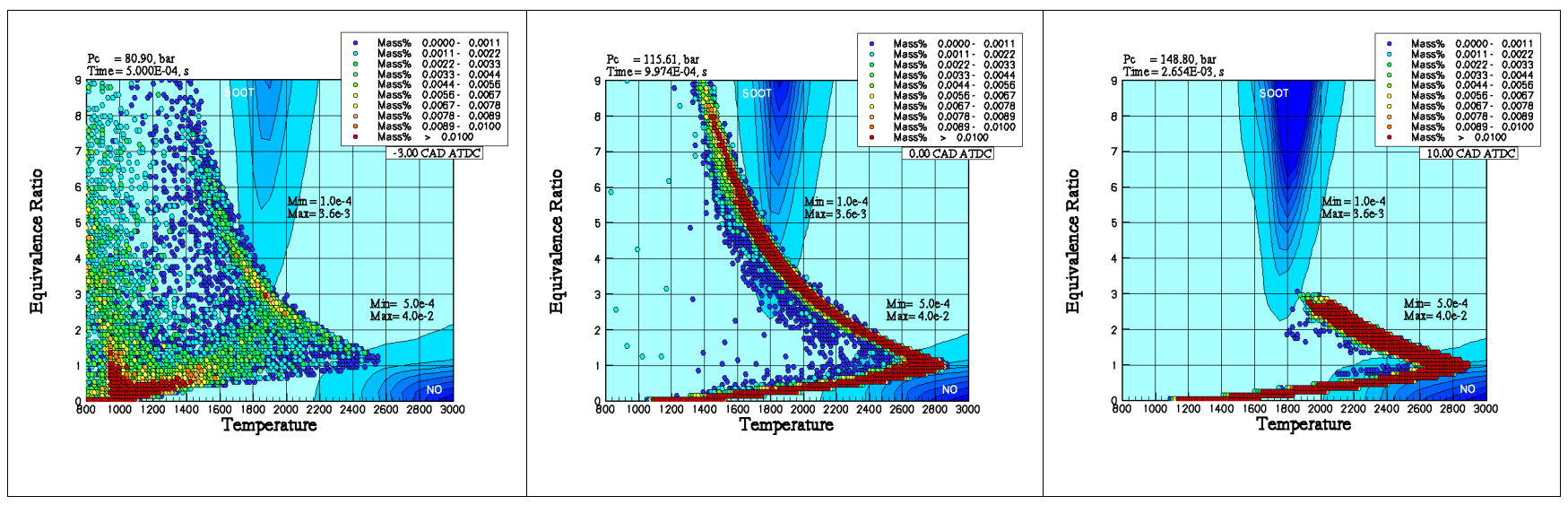

Fig. 7 The Soot-NOx map and time histories of the cell parameters corresponding to 3 different CADs, i.e., $-3,0$ and 10, for the conventional Diesel injection.

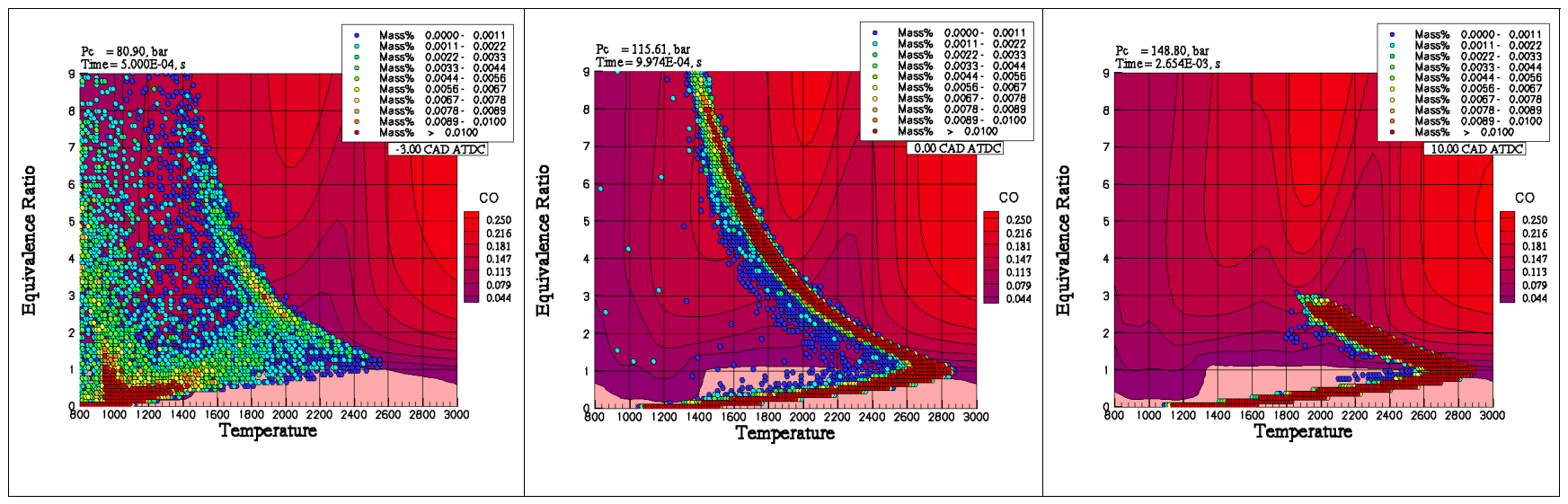

Fig. 8 The CO map and time histories of the cell parameters corresponding to 3 different CADs, i.e., $-3,0$ and 10 , for the conventional Diesel injection.

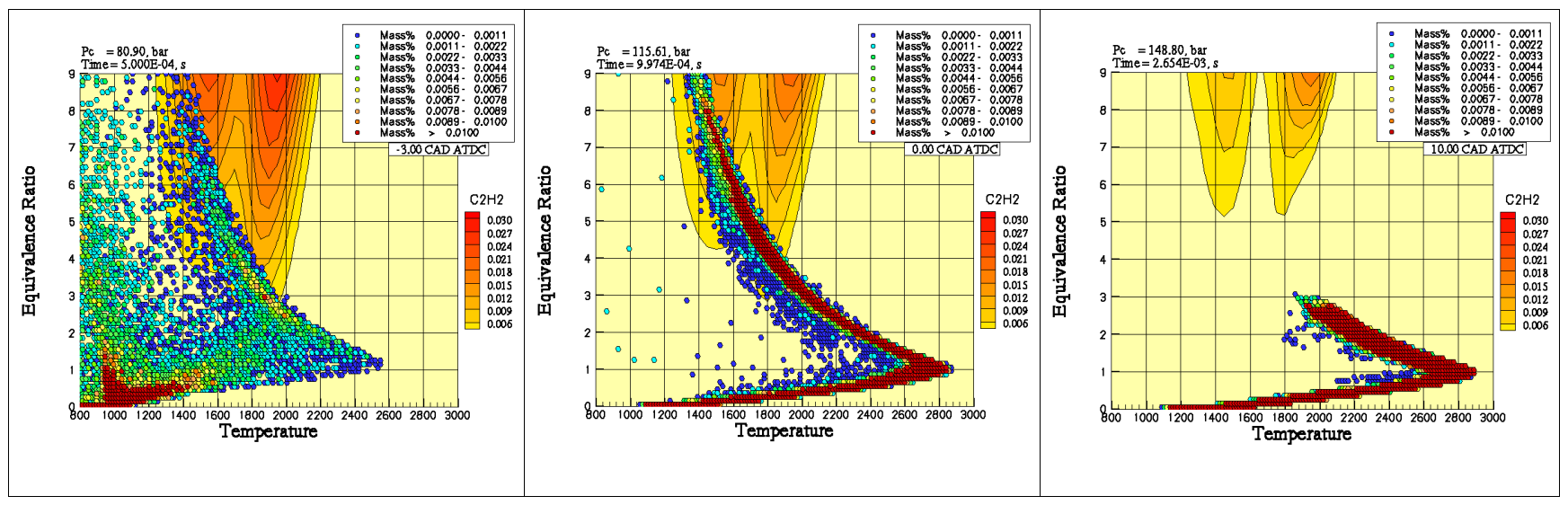

Fig. 9 The $\mathrm{C}_{2} \mathrm{H}_{2}$ map and time histories of the cell parameters corresponding to 3 different CADs, i.e., $-3,0$ and 10, for the conventional Diesel injection. 
The identical chemical mechanisms were used both in the map construction and in the engine simulations. Instead of the conventional fuel to air equivalence ratio, the chemical equivalence ratio based on a full mixture composition has been used to construct the maps.

The results obtained in the parametric map analysis are summarized in Fig. 7-Fig. 9. Another set of data is plotted in Fig. 18-Fig. 21 on page 204. When a cluster of cells intersects the peninsulas of emissions formation, as those in Fig. 7, it characterizes the process of their formation. Another advantage of the analysis developed is that it is possible to obtain the maps of different chemical species characterizing the formation of products of non-complete combustion, for example, CO (Fig. 8 refers) and soot precursors, acetylene, and $\mathrm{C}_{2} \mathrm{H}_{2}$ (Fig. 9 refers).

From Fig. 7 one can conclude that soot is formed during the initial stage of combustion, while NOx is produced after the main combustion is completed. Soot formation is maximized close to the TDC. From Fig. 8, it follows that $\mathrm{CO}$ is formed in abundance when rich mixture burns. Soot precursor, $\mathrm{C}_{2} \mathrm{H}_{2}$, distributions are changing its specific shape forming a second peninsula, since acetylene is consumed in the soot formation region.

Soot precursor formation takes place in both the lower and higher temperature sides of the soot formation region. It is possible also to present in the same way maps for other species included into the reaction mechanism.

\subsection{Chemistry-turbulence interaction model}

Most methods in simulating reacting flows involve numerical solutions of the Reynolds Averaged Navier Stokes (RANS) equations. The key element of any reliable turbulent combustion model is the incorporation of two distinct mechanisms in the turbulent mixing-macro- and micro-mixing. To account for the effect of mixture imperfections, the generalized PaSR model has been employed (Golovitchev et al., 2003). The original PaSR model introduced by Villermaux and Devillon (1972) is a simple form of the IEM (Interaction by Exchange with the Mean) approach. Let us describe briefly the original IEM model accounting for a Lagrangian particle age repartition inside the reactor. Particles representing species concentration injected into the reactor are heated by mixing with the more aged ones and are reacting in the reaction zones with the premixed mixture. The particle mixing rate depends on the micro-mixing time scale, $\tau_{\max }$. The set of the time transient equations governing the species concentrations in the reaction zone can be read as:

$$
\frac{d c}{d t}=\frac{<c>-c}{\tau_{\text {mix }}}+f_{r}(c, T) ; \quad c(t=0)=c_{0}
$$

where $\mathrm{c}$ is the instantaneous species molar density in the reacting zone, $\mathrm{T}$ is the mixture temperature, and $f_{r}(c, T)$ is the chemical source term; the brackets denote an averaging procedure; species indices are omitted for simplicity. The mean value $\langle c\rangle$ is the integral weighted by the pdf (probability density function), $p(c)$, describing the species repartition, i.e.,

$<c>=\int_{0}^{1} c \cdot p(c) \cdot d c$

By assuming ergodicity for the concentration repartition for a given time and the particle age repartition in the reactor, it follows:

$$
p(c) \cdot d c=\phi(t) \cdot d t
$$

where $\phi(t)$ is a random function of a deterministic variable $t$. This function was taken in a form of the exponential distribution, $\phi\left(1 / \tau_{r}, t\right)=\mathrm{e}^{-t / \tau} / \tau_{\mathrm{r}}$ where $\tau_{\mathrm{r}}$ is the mean residence time of particles in the reactor.

The exponential distribution is a reduced form of the Poisson distribution with one discrete occurrence or "arrival" in the course of the residence time. Finally, the averaging procedure was defined as:

$<c>=\int_{0}^{\infty} c(t) \cdot \phi(t) \cdot d t$

This model is known as the PaSR (Partially Stirred Reactor) model. The more theoretical foundation of the model can be found in Fox (2003, pp. 153-155). The description above illustrates the coupling between two approaches used in the turbulent combustion modeling.

In the extended PaSR model (Golovitchev et al., 2003), the averaging procedure described by equations (7)-(9) is replaced by numerical solution of the conservation equations of spray combustion obtained on the computational grid in which each cell represents the reactor, thus giving the values of $<c>$ and other flow parameters. The cells of the 
computational grid can be interpreted as the particles representing the mixture composition in the original IEM model. The numerical solution is based on the operator-splitting procedure applied to the mass conservation equations for species included in the multi-step reaction mechanism. In terms of this approach, the time differencing was performed in three steps: the first step was assumed to be the convection contribution, the second one is the diffusion effect without a contribution of micromixing and the third step is the chemical kinetics coupled with micro-mixing. The last step can be interpreted as combustion in a constant volume Partially Stirred Reactor (PaSR) of a computational cell size, where reactions occur in a fraction of its volume described by the system of ODEs, i.e.,

$\frac{d<c>}{d t}=\frac{<c^{1}>-<c^{0}>}{\tau}=\frac{c^{1}-c^{0}}{\tau}=f_{r}(c, T)$

Above, the chemical source term is calculated using the reactor virtual concentrations, $\tau$ is the time integration step; the averaging symbol is omitted hereafter.

The model distinguishes among the concentration (in molar density) at the reactor exit, $\mathrm{c}^{1}$, the concentrations in the reaction zone, $\mathrm{c}$, and in the feed, $c^{0}$. As time proceeds, $c^{1}$ trades place for $c^{0}$. See Fig. 10 for details.

In the case of $c \equiv c^{1}$, the system (10) can be solved by conventional numerical methods, e.g., by the kinetics program of the Chemkin package. Otherwise, these equations are "unclosed", since two sets of unknowns, $c^{1}$ and $c$, must be found. To close the system (10), a steady-state form of equation (6) can be taken leading to the equations:

$$
\frac{c^{1}-c^{0}}{\tau}=\frac{c^{1}-c}{\tau_{\text {mix }}}=f_{r}(c, T)
$$

which now can be routinely solved.

For example, in the case of the linear Arhenius kinetics $f_{r}(c, T) \equiv-c / \tau_{c}$, one can get:

$$
\frac{c^{1}-c^{0}}{\tau}=-\frac{c-c^{1}}{\tau_{\operatorname{mix}}} \quad ; \quad \frac{c-c^{1}}{\tau_{\operatorname{mix}}}=-\frac{c}{\tau_{c}}
$$

where $\tau_{c}$ is the characteristic chemical reaction time.

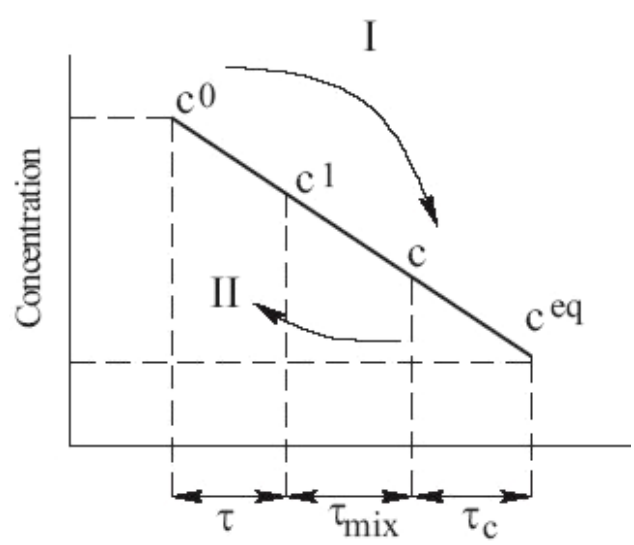

Fig. 10 The rate diagram of processes for the PaSR model; I denotes the chemical reaction, II micro-mixing.

Equations (12) are illustrated by the reaction diagram of the PaSR model presented in Fig. 10. The second portion of equation (11) expresses the main idea of the EDC model "mixing-reacting". After algebraic manipulations, the above problem solution can be represented in a form

$\frac{c^{1}-c^{0}}{\tau}=-\left(\frac{c^{1}}{\tau_{c}}\right) \cdot \kappa=-\frac{1}{2} H\left(\frac{c^{1}}{\tau_{c}}, \frac{c^{1}}{\tau_{\text {mix }}}\right)$

where $\kappa=\tau_{c} /\left(\tau_{m i x}+\tau_{c}\right)$, and $\mathrm{H}$ is a harmonic mean.

Equation (13) shows that the turbulent combustion time is the sum of the micro-mixing and reaction times, if the process is expressed in terms of the reactor exit parameters. This is the main consequence of the PaSR model. For the detailed chemical mechanism, the net production rate of the so-called reference s-species due to the chemical reaction with accounting for the micro-mixing effect can be given in a form

$\frac{c_{s}^{1}-c_{s}^{0}}{\tau}=f_{r}\left(c^{1}\right) \cdot \kappa=\frac{c_{s}^{0} f_{r}^{0}}{c_{s}^{0}+\operatorname{term}_{r}^{-} \tau+\text { term }_{r}^{-} \tau_{\text {mix }}}$

where fr0 and termr- are the net chemical production rate and the term representing total mass depletion rate, i.e.,

$$
f_{r}(c)=\left(v_{r}^{\prime \prime}-v_{r}^{\prime}\right) \dot{\omega}_{r}(c)=\text { term }_{r}^{+}-\text {term }_{r}^{-}=\text {term }_{r}^{+}-c_{s} / \tau
$$

In the above, $v_{r}^{\prime \prime}$ and $v_{r}^{\prime}$ are stoichiometric coefficients of the backward and forward stages, 
$\dot{\omega}_{r}$ is the rate progress variable of the r-reaction, respectively.

Equation (14) can be deduced, if the chemical reaction times $\tau c$ are formally defined as characteristic times of the species destruction rates, the species chemical production terms are presented as in equation (15). Micro-mixing time is described in terms of Kolmogorov's time definition (Golovitchev et al., 2003).

The references species formally defined as the species with a smallest concentration among those defining the depletion rate in the linear form (15). In this sense, they are similar to the limiting (deficient) species of the Magnussen-Hjertager, EDC model (Magnussen and Hjertager, 1976). The introduction of such a reference species for each reaction helps to approximate the nonlinear rate expression termr- by the linear one, cs/ $/ \mathrm{c}$. Substituting the expression (15) into the formula (14), one can get

$f_{r}(c)=\left(\operatorname{term}_{r}^{+}-c_{S} / \tau_{c}\right) \frac{\tau_{\mathcal{C}}}{\tau_{c}+\tau_{\text {mix }}}=\operatorname{term}_{r}^{+} \frac{\tau_{\mathcal{C}}}{\tau_{c}+\tau_{\text {mix }}}-\frac{c_{S}}{\tau_{c}+\tau_{\text {mix }}}$

Accounting for the chemical equilibrium conditions $\operatorname{fr}(\mathrm{c})=0$, i.e., termr $+=\mathrm{cseq} / \tau \mathrm{c}$, the expression (16) in the limit $\tau \mathrm{c} \rightarrow 0$ reduces to:

$$
\lim _{\tau_{c} \rightarrow 0} f_{r}(c)=\frac{c_{s}^{e q}-c_{s}}{\tau_{m i x}}
$$

that perfectly complies with the rate expression of the classic EDC model.

\subsection{Chemical and micro-mixing times definitions}

The chemical reaction times $\tau_{c}$ are formally calculated as characteristic times of the depletion rates, if the species chemical production rates are presented as in (15). In this way, for every reaction of the mechanism, chemical times can be attributed to species participating in the depletion stage leading to the definition $f_{r}(c)=-k_{r} c_{i} c_{k} \approx-c_{i} / \tau_{c, i} \approx-c_{k} / \tau_{c, k}$, where $i, k$ are species indices. In terms of the EDC model, the shortest of these times is restricted from below by the micro-mixing time, thus explaining the usage of deficient (limiting) species in the rate expression of the original EDC Magnussen-Hjertager model. In a limiting case of chemical equilibrium, the models become identical.

The accurate definition of the micro-mixing time is a matter of importance for any EDC turbulent combustion model. The micro-mixing time definition used is applicable to the system with "natural" mixture non-uniformities and based on the $\beta$-model proposed by Frisch (1995). In terms of this approach, at each stage of the Richardson vortex cascade, the number of eddies formed from a given "parent" eddy is chosen such that the fraction of volume occupied by "active" eddies is decreased by a factor $\beta<1$. In this way, the turbulent intermittency is introduced in a geometrical form of fractal dimensionality D. Coupled with the $k-\varepsilon$ model of turbulence, the viscous dissipation (micromixing) time can be derived as

$$
\tau_{\text {mix }}=\left(\frac{k}{\varepsilon}\right)^{\alpha}\left[\left(\frac{v}{\varepsilon}\right)^{1 / 2}\right]^{(1-\alpha)}=\left(\frac{k}{\varepsilon}\right) \cdot\left(c_{\mu} / \operatorname{Re}_{t}\right)^{\frac{1-\alpha}{2}}
$$

where $\alpha=\frac{3(D-3)}{1+D}, k$ and $\varepsilon$ are the turbulent kinetic energy and energy dissipation rate, respectively. From experiments reported in Sreenivasan and Meneveau (1986), it follows that the fractal dimension for turbulent dissipation is about $\mathrm{D}=2.7$, i.e.,

$$
\tau_{m i x}=\left(\frac{k}{\varepsilon}\right) \cdot\left(c_{\mu} / \operatorname{Re}_{t}\right)^{0 . \overline{621}}
$$

In the Above, bar denotes a periodic fraction. In particular, the eddy break-up time $\sim k / \varepsilon$ corresponds to $\mathrm{D}=5$; the Kolmogorov micro-scale time $\tau_{\mathrm{k}}=(\mathrm{v} / \varepsilon)^{1 / 2}-$ to $\mathrm{D}=3$.

\subsection{Spray models}

Most of the spray models implemented in the KIVA3V, rel. 2 code were left unchanged. The simulation of a spray liquid core fragmentation starts by injecting droplets with prescribed attributes (size, velocity, and temperature) of initial parameters which are usually derived from experiments. Since for the present analyses no experimental data were available, the initial droplets parameters are derived from empirical correlations, depending on Weber and Laplace numbers and gas to fuel density ratio valid for a single high-pressure injector, as proposed in the work of Bayvel and Orzechowski (1993). 
According to this approach, initial spray cone angle, droplet Sauter mean diameter and injection duration at different injection pressures are determined from fuel properties and gas conditions at Start of Injection, SOI. Since the modeling of multiple injections has to be realized on a relatively coarse computational grid, the standard droplet collision model implemented in the KIVA3V code was replaced by another one, which employs an algorithm based on the approach used in the molecular dynamics (Gustavsson, Golovitchev and Helmantel, 2004). According to this model, the colliding droplets not necessarily belong to the same computational cell that substantially reduces the model grid dependence. The original TAB model of the KIVA3V code has been replaced by the Wave Breakup Model (Reitz, 1987) which assumes that the time of breakup and the resulted droplet sizes are derived from the jet linear instability (Kelvin-Helmholtz, Raleigh-Taylor mechanisms) analyses. Since no experimental measurements were available for the engine analyzed in this study, any quantitative comparison has not been possible. Thus, the constants of the spray and combustion models have not been tuned and standard values have been used.

\section{SIMULATED ENGINE CASES}

In the simulations, a 360-degree Cartesian mesh ( $66 \times 66 \times 65$ cells in the squish and stroke regions and $44 \times 44 \times 26$ in the bowl regions as shown in Fig. 11) has been used with an overall cell number equal to 338,000 . The cell dimension has been chosen in order to minimize the grid dependence on the spray penetration and shape. The choice has been made accordingly to previous studies carried out by the authors and more details can be found in the work of Golovitchev et al. (2005).

The engine operating conditions used in the modeling are listed in Table 2 and injection parameters in the Table 3. The amount of Urea solution injected cannot be arbitrary reduced since the deoxidizing agent must be transported by the spray to the region where NOx are formed.

When injecting water / Urea solution, different Urea mass percentages have been tested: pure Urea ("pure" or " $100 \%$ " Urea is introduced in the modeling as a parametric limit only, since pure Urea is a solid substance), $80 \%$ Urea, 50\% Urea and $20 \%$ Urea.

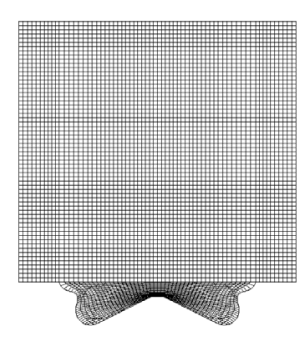

(a)

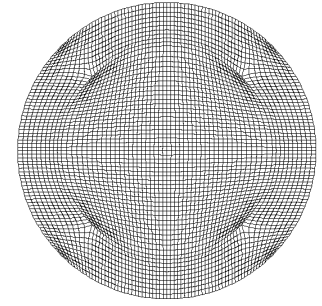

(b)
Fig. 11 (a) Cross-sectional and (b) top views of the KIVA3V mesh for the simulated engine.

Table 2 Engine specifications

\begin{tabular}{|l|l|}
\hline Bore $[\mathbf{m m}]$ & 130 \\
\hline Stroke $[\mathbf{m m}]$ & 126 \\
\hline Compression ratio & 15.4 \\
\hline Injection system & CR Direct Injection \\
\hline Bowl diam. [mm] & 92.0 \\
\hline Number of injector nozzles & 7 \\
\hline Nozzle diameter [mm] & 0.30 \\
\hline
\end{tabular}

Table 3 Injection strategies

\begin{tabular}{|l|c|c|c|}
\hline Case \# & $\mathbf{1}$ & $\mathbf{2}$ & $\mathbf{3}$ \\
\hline Speed [rpm] & 1000 & 1000 & 1000 \\
\hline $\begin{array}{l}\text { Inj. Diesel fuel } \\
\text { mass \& timing } \\
\text { [mg/st@CAD] }\end{array}$ & $124.5 @-6$ & $124.5 @-6$ & $124.5 @-6$ \\
\hline $\begin{array}{l}\text { Inj. water mass } \\
\text { \& timing } \\
\text { [mg/st@CAD] }\end{array}$ & 0 & $72.5 @+15$ & 0 \\
\cline { 3 - 3 } & & $72.5 @+30$ & \\
\cline { 3 - 4 } $\begin{array}{l}\text { Inj. water / } \\
\text { Urea solution } \\
\text { mass \& timing } \\
\text { [mg/st@CAD] }\end{array}$ & 0 & $72.5 @+45$ & $72.5 @+15$ \\
& & $72.5 @+30$ \\
\end{tabular}

\section{RESULTS AND DISCUSSIONS}

Several cases were considered: the injection of pure Diesel oil surrogate, the injection of Diesel oil followed by the injection of water and the injection 
of Diesel oil followed by the injection of Urea dissolved in the water in different proportions at different SOIs, as can be seen in Table 3. At first, the integrated in-cylinder parameters, such as incylinder pressure, Rate of Heat Release, RoHR, Soot and NO formation vs. CAD histories are presented in Fig. 12.

From Fig. 12(a) it follows that the pressure in the engine cylinder reaches 165 bar and the Rate of Heat Release is predicted about $700 \mathrm{~J} / \mathrm{CAD}$, characterizing an intensive combustion regime. Urea injection leads to the secondary heat release, whose intensity reaches about $200 \mathrm{~J} / \mathrm{CAD}$. In the pressure trace, one can see the secondary pressure rise due to the Urea injection. These pressure growth and energy release are due to the fact that the water / Urea solution represents a "real" co-fuel for the Diesel oil with a noticeable heat release effect, if it decomposes.

From Fig. 12(b) it follows that a substantial amount of Soot formed after the main combustion phase is rapidly oxidized by an access of oxygen. The presence of water or Urea does not change significantly the maximum Soot oxidation rate. Fig. 12(c) shows that the presence of Urea leads to a remarkable reduction, by $77 \%$, from the initial level of NO formed during the main phase of combustion, while the water injection does not lead to a noticeable reduction of NO.

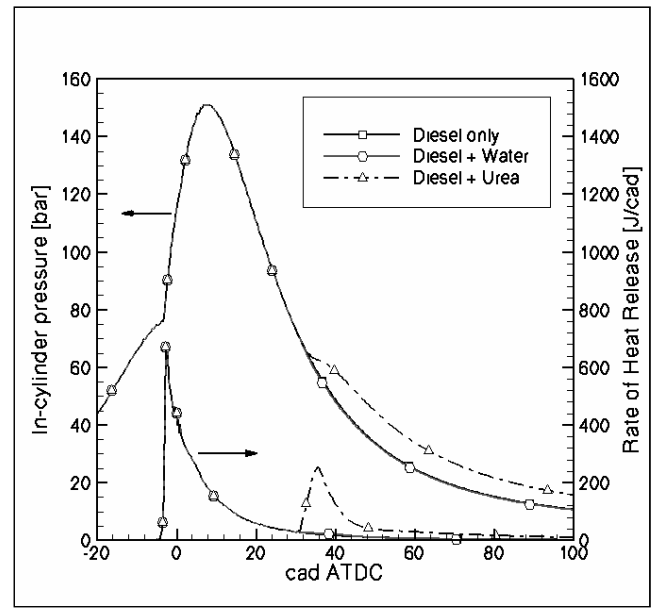

(a)

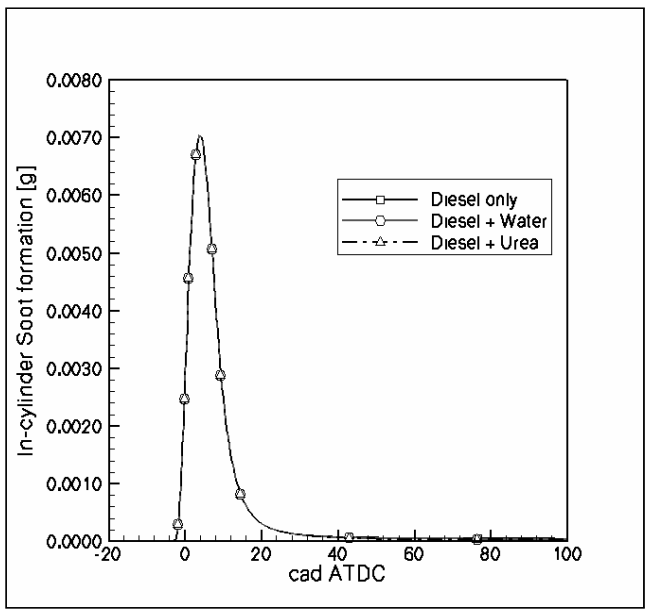

(b)

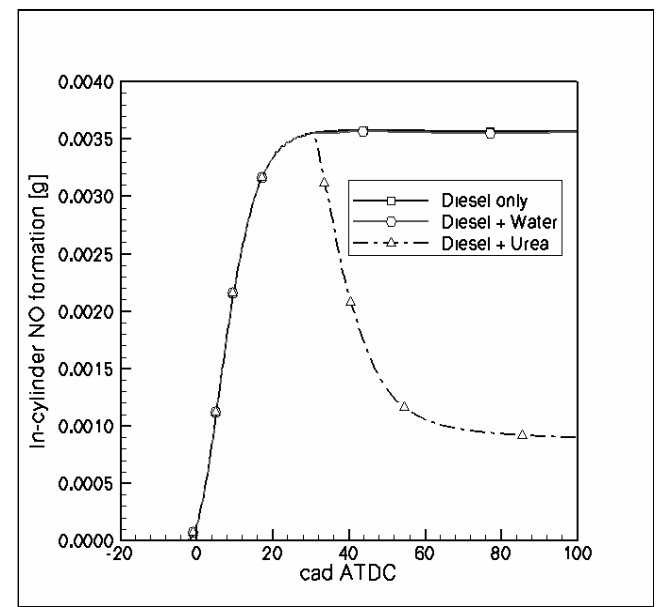

(c)

Fig. 12 Calculated (a) in-cylinder pressure and rate of heat release, (b) Soot and (c) NO formation vs. CAD corresponding to the injection strategies: Diesel oil only, Diesel oil plus water and Diesel oil plus pure Urea (water and Urea are injected at +30 CAD ATDC). 
The results of computations in terms of local temperature and NO distributions are compiled in galleries of plots corresponding to different CAD positions, presented in Fig. 13 and Fig. 14. Plots include both top and side views: top views show the cross section located $50 \mathrm{~mm}$ from the engine head; side views show cross sections passing through the spray axis.

From temperature distributions corresponding to the crank angles after the main phase of combustion
(CADs > 30) it follows that the injection of water substantially reduces the temperature of the combustion products, if comparing distributions in Fig. 13(a) and (b). However, the amount of NO was not substantially changed by the water injection as it can be concluded from the comparison of Fig. 14(a) and (b). The Urea injection causes a noticeable temperature growth, as shown in Fig. 13(c); nevertheless, a substantial reduction of NOx is illustrated in Fig. 14(c).

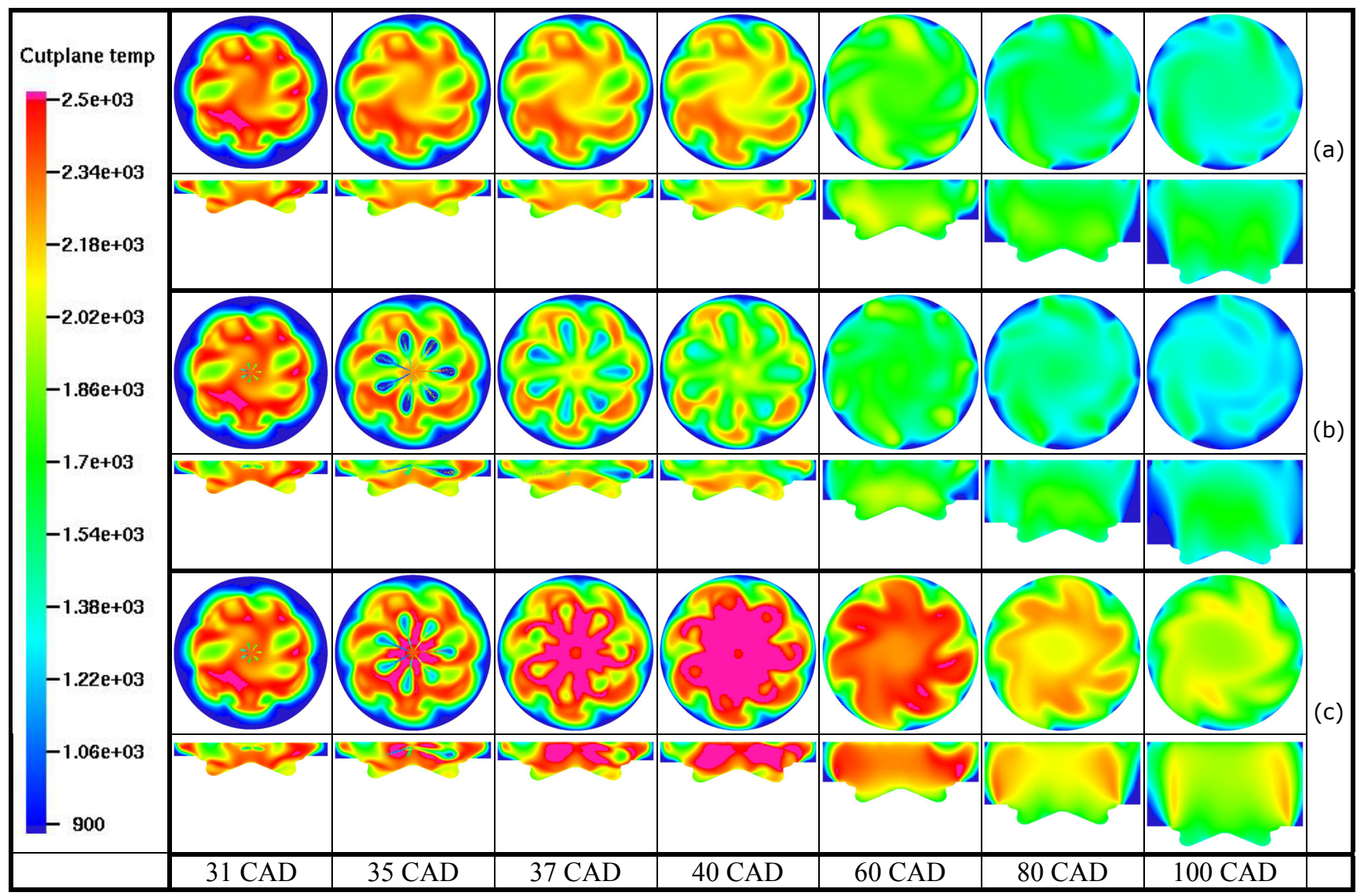

Fig. 13 Galleries of numerical results representing temperature distribution at different CADs for (a) Diesel injection, (b) Diesel and water injection and (c) Diesel and pure Urea injection cases (water and Urea are injected at $+30 \mathrm{CAD}$ ATDC). 


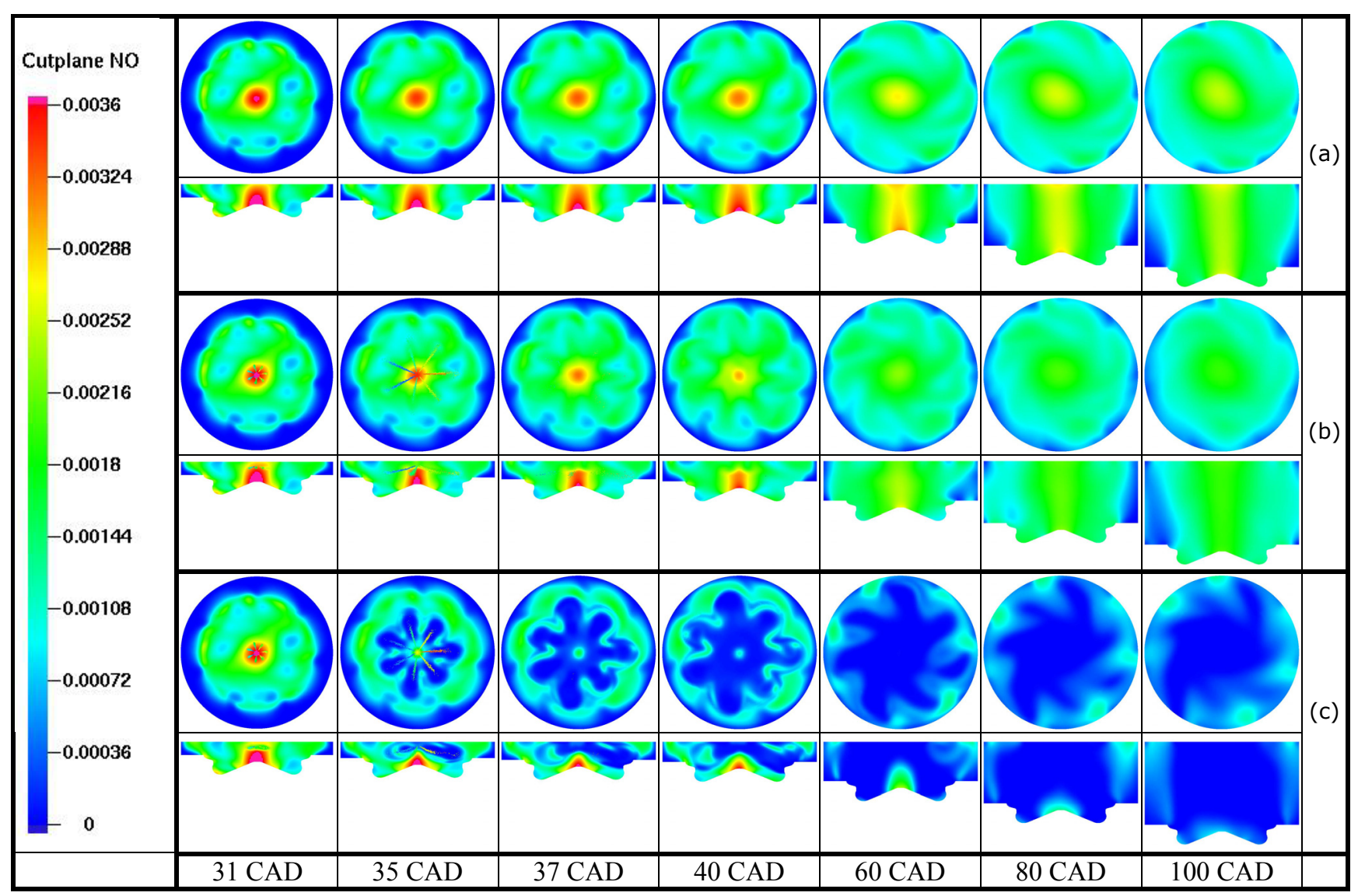

Fig. 14 Galleries of numerical results representing NO distribution at different CADs for (a) Diesel injection, (b) Diesel and water injection and (c) Diesel and pure Urea injection cases (water and Urea are injected at +30 CAD ATDC).

The results of simulations corresponding to different water and Urea injection timings and water/Urea proportions in the solution are summarized in Fig. 15-Fig. 17. In Fig. 15, one can see that delayed Urea injection leads to reduced heat release rates, affecting the in-cylinder pressure differently.

The results presented in Fig. 16 illustrate the efficiencies of both deoxidizing agents, water and Urea, injected at different SOIs. The effect of water injection on NO oxidation process was found negligible, while the late Urea injection leads to substantial reduction of NO. Since the difference between Urea $\mathrm{SOI}=30 \mathrm{CAD}$ and $\mathrm{SOI}=45 \mathrm{CAD}$ is small, this CAD interval represents the optimal window for Urea injection. The trends of NO and Soot reduction by water and Urea as function of the injection timing and the water / Urea proportions in the solution are plotted Fig. 15-Fig. 17. The results illustrate that $\mathrm{NOx}$ reduction is not strictly proportional to the amount of Urea in the solution. For example, for $\mathrm{SOI}=15 \mathrm{CAD}$ the maximum reduction is achieved for $20 \%$ and $50 \%$ Urea content in the solution. For SOI $=30 \mathrm{CAD}$, the NOx reduction predicted appeared to be similar for all proportions. In the case of late secondary injection, $\mathrm{SOI}=45 \mathrm{CAD}$, the maximum reduction was achieved for $50 \%$ Urea content. These results illustrate the prospect of Urea amount reduction used in the NO deoxidizing process.

Similar results on $\mathrm{CO}$ and Soot reductions are also presented in Fig. 17. The results illustrate that late water/Urea injection can lead to substantial reduction of both emission agents, while early injection can even lead to growth of carbon monoxide content.

The residual amounts of Urea and products of its decomposition are reducing rather slowly, requiring a considerable amount of time to be converted into $\mathrm{N}_{2}$ and $\mathrm{H}_{2} \mathrm{O}$. In the case of a high engine speed (rpm $>1500)$, these residuals could be large. The usage of water / Urea solution allows injecting the oxidizing agents earlier into the high temperature regions, since the water evaporation reduces the temperature to a level advantageous for the NO reduction process. 


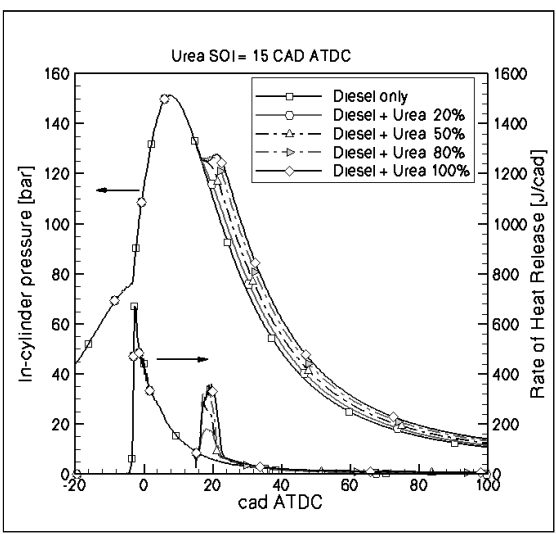

(a)

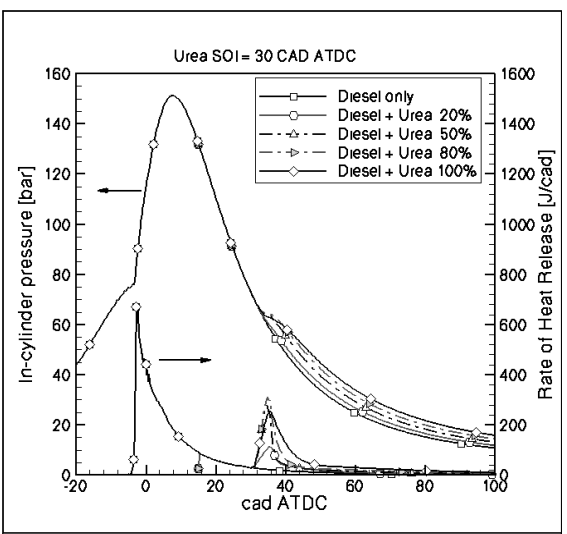

(b)

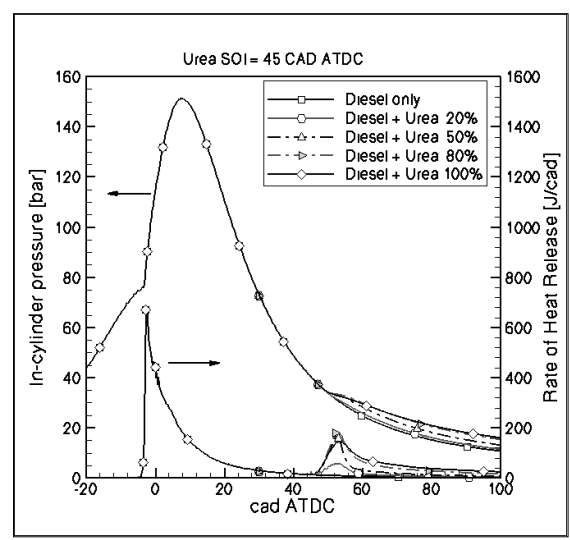

(c)

Fig. 15 In-cylinder pressure and rate of heat release for water / Urea solution injection at different SOIs and for different Urea mass percentages in the solution.

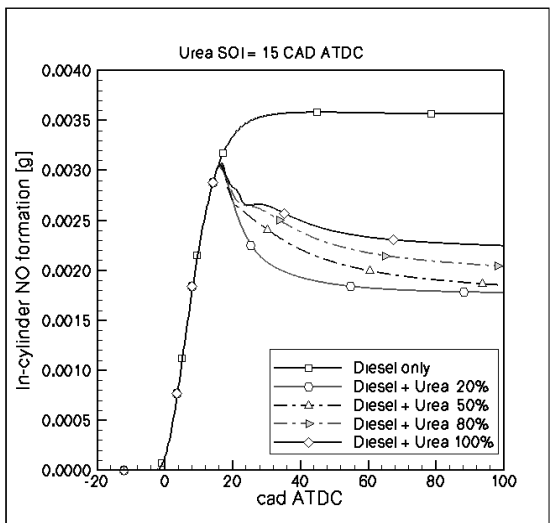

(a)

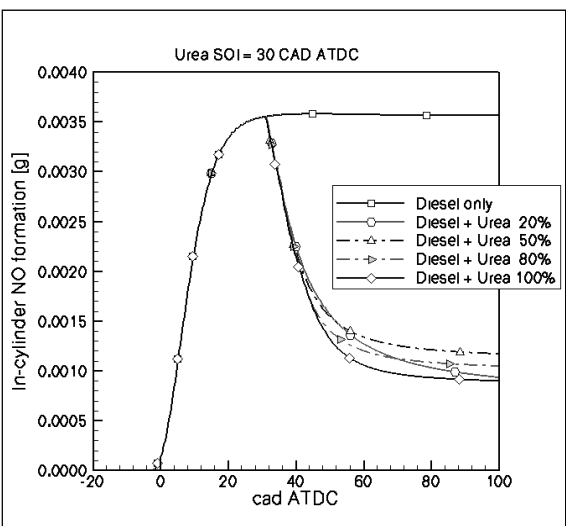

(b)

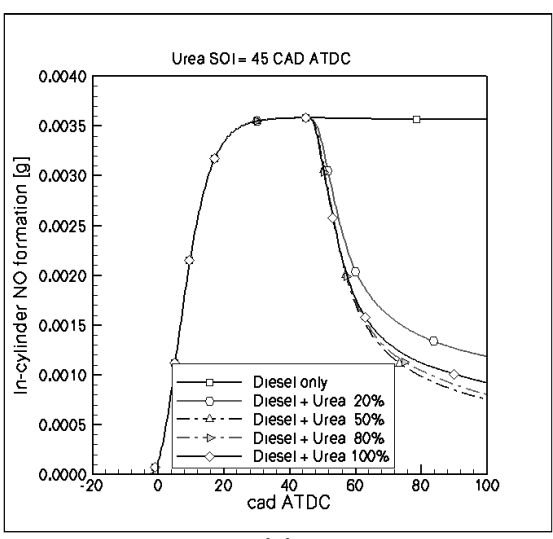

(c)

Fig. 16 NO formation for water / Urea solution injection at different SOIs and for different Urea mass percentages in the solution.

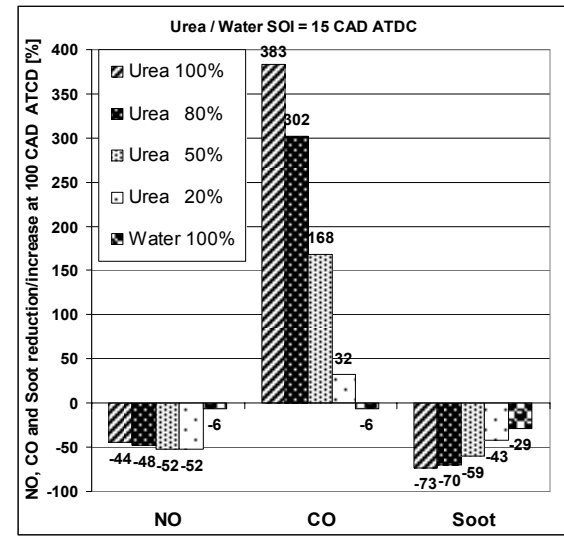

(a)

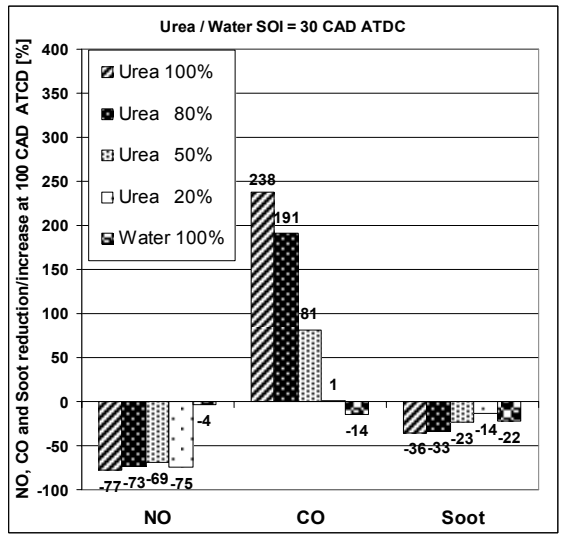

(b)

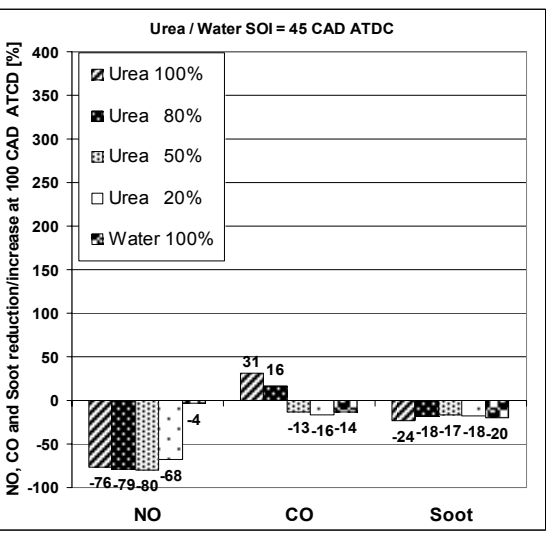

(c)

Fig. 17 Final NO, CO and Soot reduction/increase with respect to the Diesel only case: comparison for water / Urea solution injection at different SOIs and for different Urea mass percentages in the solution. 


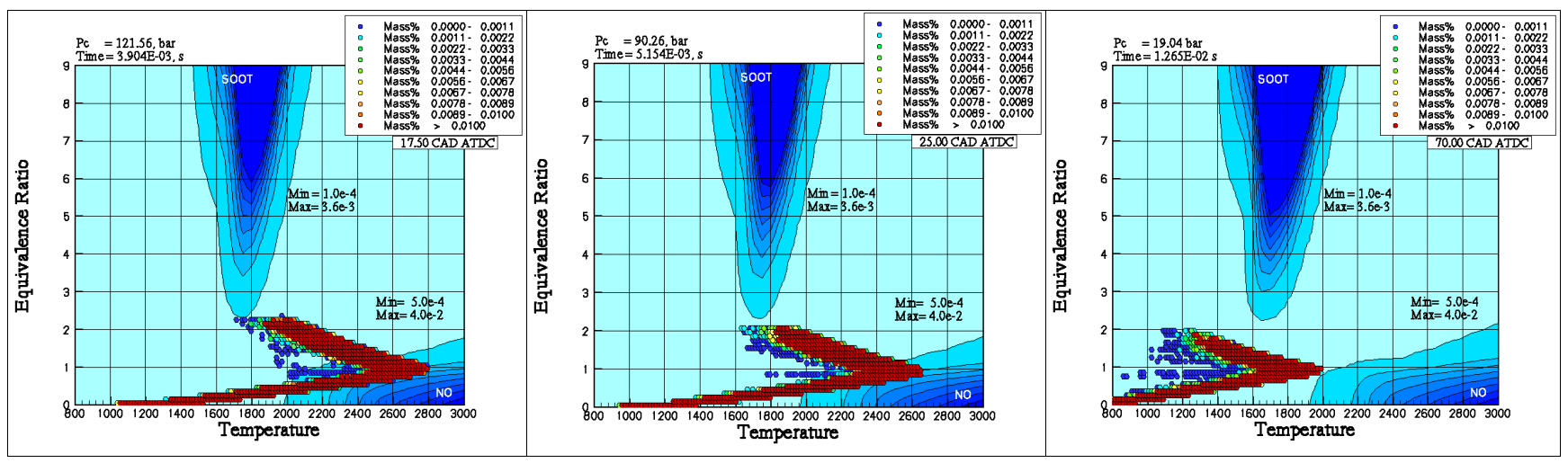

Fig. 18 The Soot-NO map and time histories of the cell parameters corresponding to 3 different CADs, i.e., 17.5, 25 and 70 , for the conventional Diesel injection.

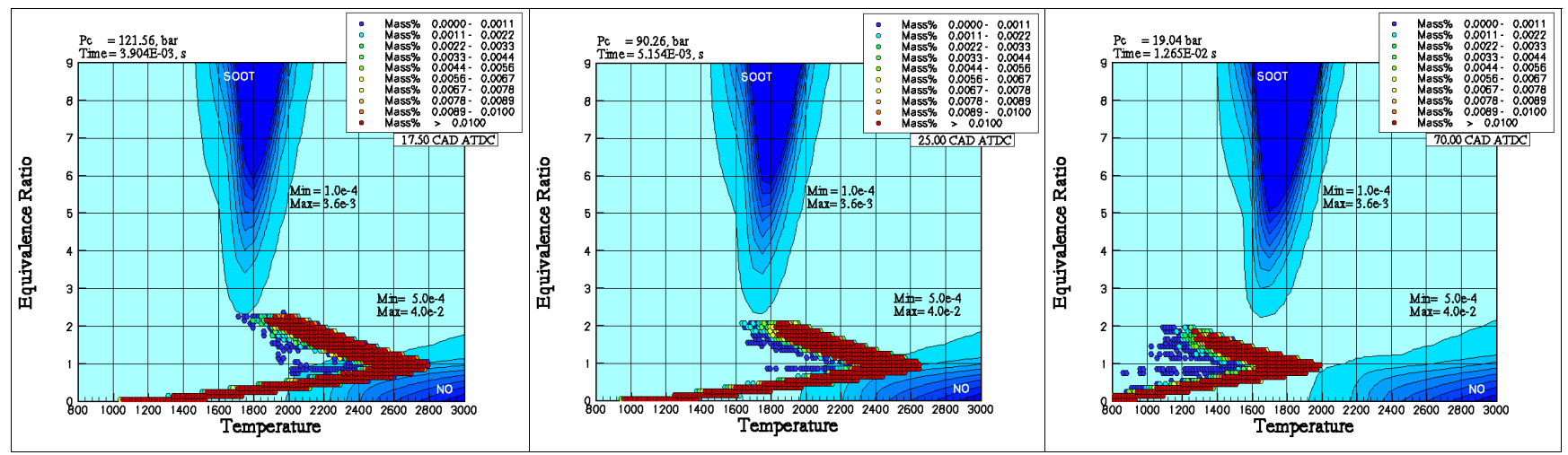

Fig. 19 The Soot-NO map and time histories of the cell parameters corresponding to 3 different CADs, i.e., 18, 25 and 70, for the Diesel+water injection case (water injection timing: +15 CAD).
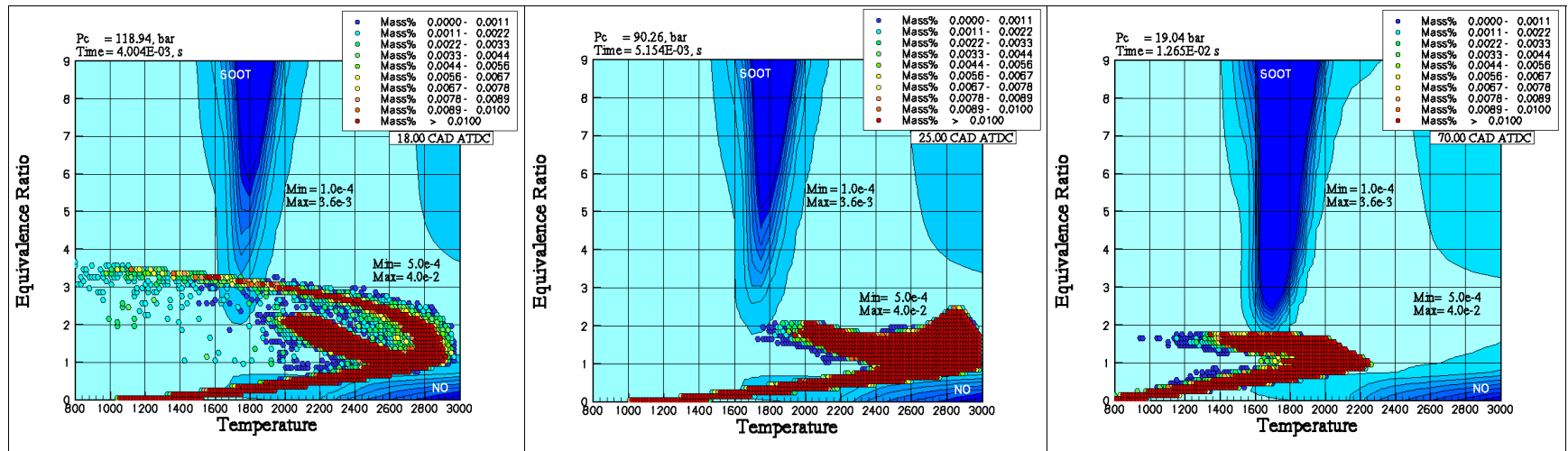

Fig. 20 The Soot-NO map and time histories of the cell parameters corresponding to 3 different CADs, i.e., 18, 25 and 70, for the Diesel+Urea injection case (Urea injection timing: +15 CAD). 


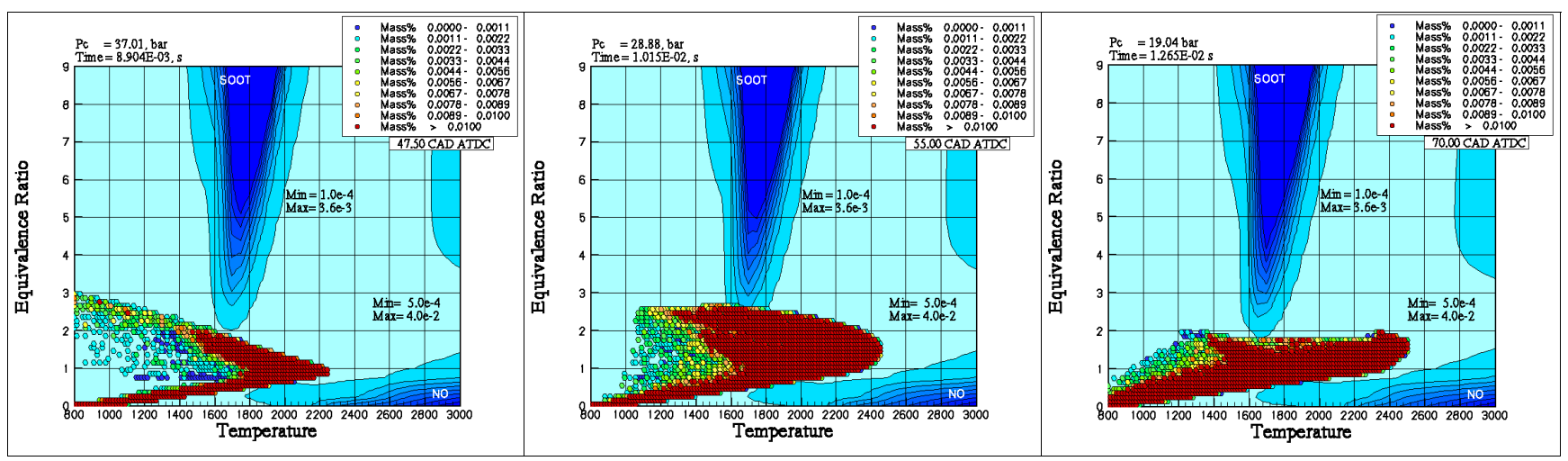

Fig. 21 The Soot-NO map and time histories of the cell parameters corresponding to 3 different CADs, i.e., 47.5, 55 and 70, for the Diesel+Urea injection case (Urea injection timing: $+45 \mathrm{CAD}$ ).

The effects of both deoxidizing agents in reducing emission, NOx and Soot are well illustrated by transient emission maps depicted in Fig. 18-Fig. 21. The maps presented in Fig. 18 correspond to the late phase of combustion development when Diesel oil surrogate has already been injected. The earlier stage of the combustion is presented in Fig. 7 on page 195. The maps in Fig. 19 and Fig. 20 correspond to the same CADs as in Fig. 18 with the different deoxidizing agents, water in Fig. 19 and Urea in Fig. 20, injected at $\mathrm{CAD}=15$. Fig. 19 illustrates that water injection leads to a substantial reduction of Soot, but barely affecting the NO reduction. In this case, the slight increase of NO is probably due to the water vapor dissociation forming $\mathrm{OH}$ radicals. Conversely, the Urea injection does not affect much the Soot oxidation, but remarkably reduces the amount of NO produced in the main stage of combustion. The effect of NO reduction by Urea injection is better pronounced for the latest injection, $\mathrm{SOI}=45$, as seen in Fig. 21 . The residuals of Urea and ammoniac compounds can be kept negligible, if the relatively early, SOI $\leq$ $30 \mathrm{CAD}$, secondary injection is realized.

Since the reductions of Soot and NO by both water and Urea are effective for different injection timings, it is important to optimize the injection timing and the water / Urea proportion in the solution, the substance that combines the useful properties of both deoxidizing agents.

\section{CONCLUSIONS}

The full-scale (360-degree mesh, given number of sprays, and detailed chemistry model) CFD modeling based on the KIVA3V, rel. 2 code has been performed for the DI ( 7 sprays) Diesel IF-
1300 engine to analyze the possible NOx reduction strategy using water and water / Urea solution injections directly into the engine cylinder during the expansion stroke.

To perform the numerical analysis, the detailed chemical mechanism of Diesel oil surrogate combustion has been supplemented by a set of reactions accounting for Urea / NO interaction processes leading to conversion of $\mathrm{NO}$ into $\mathrm{N}_{2}$ and $\mathrm{H}_{2} \mathrm{O}$. The total chemical mechanism used in the modeling consists of 74 species participating in 325 reactions.

By contrast with the general practice used to reduce NOx by DeNOx processes, when ammoniac agents were added into the combustion products at reduced temperatures and pressures, a relatively early injection (from 15 to 45 CAD ATDC) of the water / Urea solution into high temperature gas has been analyzed along with different Urea mass percentages in the solution. The applicability of such an option is due to the latent heat of the water evaporation leading to a substantial reduction of the combustion products temperature. In the numerical experiments, it was found that significant reduction of NO can achieved. At these conditions, the residuals of Urea and ammoniac compounds can be kept negligible.

Since the predictions illustrate that the early secondary injection can lead to substantial amount of carbon monoxide formation, the SOI and water / Urea proportion in the solution should be accurately selected. The optimal values of these parameters of the DeNOx process were found.

The reductions of Soot, $\mathrm{CO}$ and NO by both water and Urea are effective for both agents at different injection timings, and the accurate optimization of the injection timing and Urea proportion in the 
water / Urea solution, the substance that combines the useful properties of deoxidizing agents, could be the subject of a future work. A special attention will be paid to a reduction of the amount of Urea used in the deoxidizing process.

\section{ACKNOWLEDGEMENTS}

This work was supported by the Chalmers Combustion Engine Research Center, CERC.

\section{REFERENCES}

1. Akihama K, Takatori Y, Inagaki K, Sasaki S and Dean A (2001). Mechanism of the Smokeless Rich Diesel Combustion by Reducing Temperature. SAE Paper 2001-01-0655.

2. Amsden AA (1997). KIVA-3V: A Blockstructured KIVA Program for Engines with Vertical or Canted Valves, LA-13313-MS.

3. Bayvel L and Orzechowski Z (1993) Liquid Atomization. Taylor \& Francis, pp. 250-252.

4. Canton JA and Siebers DL (1988). Comparison of nitric oxide removal by cyanuric acid and by ammonia. Western States/Combustion Institute Meeting, Paper 88-67.

5. Fox RO (2003). Computational Models for Turbulent Reacting Flows. Cambridge University Press.

6. Frisch U (1995). Turbulence, the Legacy of A.N. Kolmogorov. Cambridge University Press.

7. Golovitchev VI, Atarashiya K, Tanaka K and Yamada S (2003). Towards Universal EDCBased Combustion Model for Compression Ignited Engine Simulations. SAE Paper 2003-01-1849.

8. Golovitchev VI (2007). http://www.tfd.chalmers.se / valeri/MECH

9. Golovitchev VI, Gustavsson J, Cantore G, Montorsi L and Corcione FE (2005). Largescale CFD Approach for Spray Combustion Modeling in Compression Ignited Engines. SAE_NA ICE2005-45.

10. Gustavsson J and Golovitchev VI (2003). Spray Combustion Simulation Based on Detailed Chemistry Approach for Diesel Fuel Surrogate Model. SAE paper 2003-01-1848.

11. Gustavsson J, Golovitchev VI and Helmantel A (2004). 3-D Modeling of Conventional and HCCI Combustion Diesel Engines. SAE Paper 2004-01-2964.
12. Kusaka J (2006). Waseda University. Private Communication.

13. Lepperhof S, Huthwohl S and Pischinger F. (1992). Catalytic reduction of NOx in diesel exhaust. SAE Paper 925022, FISITA.

14. Lutz AE, Kee RJ and Miller JA (1994). SENKIN: A Fortran Program For Predicting Homogeneous Gas Phase Chemical Kinetics With Sensitivity Analysis. SAND87-8248, Sandia National Laboratories.

15. Magnussen BF and Hjertager BH (1976). On the numerical Modeling of Turbulent Combustion with Special Emphasis on Soot Formation and Combustion. 16th Symposium (International) on Combustion, Pittsburgh: The Combustion Institute, pp. 719-729.

16. Miyamoto N, Ogawa H, Wang J, Shudoh T and Yamazaki K (1993). Reduction of Diesel NOx Emission with Ammoniac Deoxidizing Agents Directly Injected into the Cylinder. JSAE-9300314.

17. Reitz RD (1987). Mechanism of Atomization Processes in High-Pressure Vaporizing Sprays. Atomization and Spray Technology 3:309-337.

18. Rota R, Antos D, Zanoelo ÉF and Morbidelli M (2002). Experimental and modeling analysis of the NOxOUT process. Chemical Engineering Science J. 57:27-38.

19. Sreenivasan KR and Meneveau C (1986). The fractal facet of turbulence. J. Fluid Mech. 173:357-386.

20. Tajima H, Takasaki $\mathrm{K}$, Takishi $\mathrm{T}$ and Murakami S (2006). The Effect of Direct Water Injection on Usteady Fuel Spray Combustion. ICLASS-2006.

21. Villermaux J and Devillon JC (1972). Représentation de la coalescence et de la redispersion des domaines de ségrégation dans un fluide par un modèle d'interaction phénoménoloqique, Proceedings of the 2nd International Symposium on Chemical Reaction Engineering, pp.1-13. 